\title{
Inter-professional collaboration in an Intensive Care Unit: Challenges and opportunities
}

\author{
Colaboração interprofissional em uma Unidade de Terapia Intensiva: desafios e \\ possibilidades
}

Eveline Rodrigues da Silva Barros ${ }^{1}$, Ana Ecilda Lima Ellery ${ }^{2}$

\begin{abstract}
Objective: to understand the relationship between health professionals in an intensive care unit, to explore the inter-professional collaboration. Methods: it is a qualitative study, inspired by the Hermeneutics Phenomenology of Paul Ricoeur, for the production of knowledge. Interviews were conducted with 36 intensive care professionals of a tertiary public hospital. Results: the professionals are satisfied with the work, and there is a commitment to provide quality care despite organizational boundaries such as precarious employment relationships and turnover of professionals. The inter-professional collaboration is an indispensable factor for assistance, but in practice is not effective most of the times by the absence of provisions for the integration of the team, leadership presence, as well as the overcrowding of services that overwhelm health workers. Conclusion: while recognizing the need for inter-professional collaboration, professionals do their work even in a very individualized way, with no strategies to boost this cooperation.
\end{abstract}

Descriptors: Interprofessional Relations; Patient Care Team; Intensive Care.

Objetivo: compreender a relação entre os profissionais de saúde, numa unidade de terapia intensiva, explorando a colaboração interprofissional. Métodos: estudo de natureza qualitativa, inspirado na Fenomenologia Hermenêutica, de Paul Ricoeur, para a produção do conhecimento. Foram realizadas entrevistas com 36 profissionais de Terapia Intensiva de um hospital terciário, público. Resultados: os profissionais estão satisfeitos com o trabalho e há empenho em prestar assistência de qualidade, apesar de limites organizacionais, como vínculos empregatícios precários e rotatividade dos profissionais. A colaboração interprofissional é fator imprescindível para assistência, mas na prática não se efetiva, em grande parte pela ausência de dispositivos para a integração da equipe, presença de liderança, bem como pela superlotação dos serviços, que sobrecarregam os trabalhadores da saúde. Conclusão: mesmo reconhecendo a necessidade da colaboração interprofissional, os profissionais, regra geral, fazem seu trabalho ainda de forma muito individualizada, não havendo estratégias que impulsione esta colaboração.

Descritores: Relações Interprofissionais; Equipe de Assistência ao Paciente; Terapia Intensiva.

\footnotetext{
${ }^{1}$ Escola de Saúde Publica do Estado do Ceará. Fortaleza, CE, Brazil.

${ }^{2}$ Universidade Federal do Ceará. Fortaleza, CE, Brazil. 


\section{Introduction}

Deprivation of liberty and autonomy, even if temporary, is a stressful experience and generates suffering for human beings. This condition extends when we talk about people who, for intrinsic or extrinsic conditions, are taken from the active society to depend not only on health care professionals but also of their families ${ }^{(1)}$. "Admission to a general intensive care unit is an event that causes extensive suffering for both the patient and the family, which is characterized as a tense, physiological and/or psychological situation, and may affect people in all their dimensions"(2:183).

In this sense, one aspect that contributes to the safety and reduces the suffering of patients and their caregivers is the collaborative work of the professional teams ${ }^{(3)}$. Miscommunications, the result of non-cooperation among health professionals, are the leading cause of accidental damage to all health care scenarios, especially in the intensive care unit, which is a dynamic, complex work environment, exposing patients continuously to the complexities of the functioning of the inter-professional team ${ }^{(3)}$. The collaborative practice happens when various health professionals with different professional backgrounds work together with patients, families, caregivers and communities to provide the highest quality care $^{(4)}$. It allows healthcare professionals to integrate any individual whose skills can help the achievement of local health goals. This practice strengthens the health systems and promotes the improvement of health outcomes $^{(4-5)}$.

Collaboration or inter-professional cooperation is presented as a strategy of teamwork and is related to an ethic of care, approaching participatory practices and mutual personal relationships among health professionals. The introduction of new paradigms in the health system, such as the principle of integration, assumes that the professionals of this area transform their practice, developing a new look for the patient, co-worker and himself, to go beyond the formal and mechanical acts. Therefore, it is necessary to establish spaces of meeting and exchanges that strengthen joint action and integration between professionals ${ }^{(5-6)}$.

Due to the complexity of the assignment and the training model still focused on the defense of the professional field to obtain status and higher earnings in the labor market ${ }^{(4)}$, many difficulties in joining the inter-professional collaboration and integration of knowledge as a method of the job are found. Among the barriers, there are the health system crumbled and services organized by professional category; fragmented care within the traditional health system that was only curative; the professional culture specialist, excess demand and the lack of resources; concentration of power and ethical obstacles ${ }^{(7)}$.

Despite the advances in technology and science, the health professional work remains of great importance to provide a more humanized and comprehensive care, being essential to interprofessional collaboration to maximize available resources. Based on this, the interdisciplinary approach and the pursuit of universal integral systems bring to the agenda the need to adopt strategies to improve the interaction between professionals, focused attention on the needs of patients and communities, and to reach better health ${ }^{(8-9)}$.

From this perspective, it was chosen to develop this study, trying to understand the relationship between health professionals in an intensive care unit, exploring if there is inter-professional collaboration.

\section{Methods}

It is a case study of a qualitative nature, inspired by the Hermeneutics Phenomenology ${ }^{(10)}$ for the production of knowledge. This author asked by what means the reading comprehension is possible, developing a hermeneutic method of textual analysis that includes distance, appropriation, explanation, understanding and interpretation. He considers that 
these are the attitudes that the interpreter/reader can take a text, to an interview ${ }^{(10)}$.

Study participants were professionals of the multidisciplinary team of an intensive care unit of a tertiary public hospital in Fortaleza, Ceará, Brazil. This intensive care unit employs about 200 professionals weekly. It has 38 beds, assisting varied type of patients, with surgical and clinical profiles. There were random approaches made to various professionals working in the intensive care unit and who were involved in the treatment of hospitalized patients with different shifts, formulating the verbal invitation to each professional, checking their interest in participating in the study. The inclusion criterion was the availability of professionals (social workers, physiotherapists, doctors and nursing staff). Professional from the general services, maintenance, and laboratory were excluded.

Data were collected using a structured questionnaire with open questions. There were about 50 forms delivered, focusing on the following topics: interaction in professional practice; how to build and implement the therapeutic project of the patient; inter-relationship; professional difficulties; team integration in patient care. These forms were completed according to the time availability of each professional, some of them took 20-30 minutes to answer. Other had a period 02-05 days for delivery. Of the 50 questionnaires delivered, 36 were returned, 24 of high-level professionals (social workers, nurses, physiotherapists, and doctors) and 12 nursing technicians.

For analysis, a thorough reading of the interviews was made, looking for core subjects, followed by sub-themes and finally meanings units. The analysis phase of the information obtained occurred in two stages ${ }^{(4)}$ : the first stage occurs before the processing of information when we systematize the subjects' answers in a format that allows summarize and organize production to see the information obtained clearly. The second stage had analytical and critical moments, occurring when the proper interpretation of the results when the hypotheses are formulated to support the treated material. It is a creative phase to elaborate explanations and interpretations.

The study complied with the formal requirements contained in the national and international regulatory standards for research involving human beings.

\section{Results}

Analyzing the interviews, it was possible to identify four empirical categories related to interprofessional collaboration: professional satisfaction with the activity they develop; interaction and interprofessional collaboration in the construction of the treatment plan; the impact of inter-professional collaboration for patient care; challenges to interprofessional collaboration. Following, we present the findings, according to the previous categories.

\section{Professional satisfaction with the activity that they develop}

Concerning job satisfaction, the subjects interviewed demonstrated to be happy professionally and very pleased to be working on an intensive care unit, where they can exercise the care to the patient as a whole, and maintain continuity. Nurses believe to be the best place to work and feel free to invest in existing technologies. For me it is the best area to work in a hospital. The nurse has autonomy and needs always to update to take care of critically ill patients (Nurse 1). They feel useful and with a unique responsibility making a difference in positive recovery treatment offered to inpatients. I feel important within the team, to play my role as a nurse (Nurse 4).

This result also shows other needs of 
professionals, related to available resources, as observed in the report of some professionals. I am gratified to be able to perform therapies that help in the evolution and improvement of the patient, but somewhat uncomfortable with the lack of material, which undermines the good work output (Physical Therapist 3).

There are references to working and pay conditions that interfere with the job satisfaction, as we see in the following statements: From a financial point of view, I feel undervalued, but from the care point of view I felt active and valued (Nurse 4). Professionally I am somewhat unmotivated. I love working on the rehabilitation of the patient's health, but I cannot be hypocritical. There is a lack of material resources that would change the patient's therapy, professional encouragement and a living wage (Nurse 6). I am very well professionally, but dissatisfied with the wage gain of the category (Nurse 9). I love my profession, but we are not valued, we have delayed wages, lack of competition, and not being heard at the meetings on our expectations, which causes a certain lack of motivation at work (Nursing Technician 7).

Another aspect mentioned by the nursing technicians was the devaluation of their knowledge, even though they are professionals who are present in patient care: I neglect of the team of nursing technicians, with overwork: we do not attend the meetings. They just give us orders without first consulting us (Nursing Technician 1). Unfortunately, I do not feel valued, because we have no space to discuss in a constructive manner, and do not feel well heard. Also, I do not shut up when I see something that does not bring benefits to the patient (Technical Nursing 8).

\section{Interaction and inter-professional collaboration in building the patient's therapeutic project}

Regarding the construction of the singular therapeutic projects of patients, this is seen as essential and of paramount importance in the final behavior of the critical patient. Through it, it is possible to have a comprehensive diagnosis and an inter-professional care plan from the perspective of comprehensive care involving biopsychosocial aspects. It is a plan where the patient and his family are also involved in the care, being built and evaluated permanently, according to the uniqueness of each subject.

For the medical category, the treatment plan is vital, but a leadership that organize the work of the team is needed. Essential as long as there is an organizer of the final behavior (Physician 1).

As for the physiotherapists, they believe that there is still much to evolve in this therapeutic project because it will have to be more support and initiative management, to strengthen the practice while acknowledging that when the team works together, adding each of their area of knowledge, the patient is assisted better. However, they consider that the management (clinical, administrative and public) seems to have awakened to this practice. The therapeutic project is of paramount importance for the evolution of the patient (Physiotherapist 3). It is essential because the more we collect information and know our patients through integration with the team, the more effective it becomes our intervention (Physiotherapist 5). I think the therapeutic project is very important but little known (Practical Nurses 1). In practice, they point out that this is not effective, largely due to overcrowding of services, which are a burden on health workers, who are focused on solving immediate problems, producing bureaucratic assistance, leaving aside the discussion of cases and the exchange of knowledge.

In the Intensive Care Unit, there are professionals working from different backgrounds such as nurses, doctors, physiotherapists, social workers, speech therapists, nutritionists, that need dialogue in the construction of the treatment plan. The subjects reported participating in the research or professionals who provide care to a particular patient having direct contact with each other, as in the example of practical nurses and social workers, who have more contact with nurses and doctors. They highlight to do not have elaborate devices contributing to team 
interaction. There is only information exchanging that are often requested by doctors or nurses to fit any therapy and not always extend to the rest of the team. What is still mandatory, it is the shift change, each for its category.

Professionals of different categories have reported no problems in interacting with each other, exchanging well the experiences and scientific knowledge that enrich and enhance the effectiveness of care. I always give my opinion when I agree or not with the behavior and have a good relationship with everyone (Nurse 1). Nurses recognize that despite the difficulties of a relationship, this interaction is important for the progress of a good care. There are the difficulties of services. Overall, a good relationship, each professional depends on the other. An adjusted staff flows well to teamwork, and patient care is efficient (Nurse 3). There is an exchange of information that promotes a differentiated care, but not always professionals, in general, are open to this experience. Most of them, the interaction between professionals is good. of course, there are relationship difficulties with other (Nurse 7). A good involvement with the team. Of course, it is more recognition by other ones (Nurse 9).

Social workers also emphasize the interprofessional collaboration being fundamental for the improvement of health care, needing to understand the patient in his entirety, including his bio-psychosocial dimension so that there is an understanding of his health. I evaluate as extremely important, considering that the patient needs to be seen from the biopsychosocial point of view, to understand his health condition (Social Worker 2).

As for nursing technicians, they find very important the inter-professional collaboration, although there are little team effort and management to make this happen. There are professionals who are more focused on operating standards in mechanistic and hierarchical work, closing to new experiences. They consider that, despite the nursing technician staff is increasingly qualifying, they are still poorly valued and heard. When asked about the interaction: It depends on the team you are working on, some of them accept the professional contributions while others almost do not stop to listen to us (Nursing Technician 2). The high-level professionals choose to hear most of the time the same level categories of education. You need to have more unity among professionals (Nursing Technician 3).

The need for leadership to organize the team's work was highlighted as essential for all professionals. A leader boss to organize the priorities is necessary (Physician 1).

\section{Impact of inter-professional collaboration for patient care}

Regarding the impact of the integrated teamwork for patient care, doctors consider that this ensures better efficacy in the treatment and less iatrogenic because it is a working that brings positive results for the patient. Yes, the integrated work brings positive results for the patient. Better efficiency and less iatrogenic (Physician 1).

Nurses feel that when there is collaboration, their work gets better, and it is good for the patient. When everything is fine, nothing has to complain, but if something goes wrong, this effect is reflected in the care. Yes, team interaction can directly influence the quality of service provided to patients. The integrated team realizes better their patient (Nurse 4). Yes. When the team is cohesive, results come faster and positive (Nurse 7). Certainly, a team that has a good relationship leads to a better development of activities at work, resulting in better patient care (Physiotherapist 7).

Physiotherapists realize that there is a positive impact of the integrated work, but there will always be an opportunity to improve in the advances in the multidisciplinary care plan, which must be individualized to the patient, resulting in improved care.

Social workers say that despite the difficulties previously mentioned, they observed in specific 
situations the impact of inter-professional collaboration for patient care, as well as their satisfaction with the work, making it more efficient and effective, which favors the therapeutic process. Despite the difficulties of social service described previously, it is observed in specific situations, the impact of teamwork for patient care, as well as the satisfaction of families (Social Worker 3). However, they recognize that any action discontinuous, with administrative bureaucracy barriers, ending up surpassing all the knowledge of the multidisciplinary team, for the principle of integration involving promotion, online assistance, and care, in cooperation with horizontal and vertical work.

Nursing technicians say better understand this impact when other professionals recognize their work and also when they receive feedback from the patient, referring satisfaction with the care received. They consider that the praise of patients and families are reflections of a good job, and they get valued. Yes, when I see the patient's satisfaction with the good assistance by all. Often we hear praise. This is a reflection of our good work (Nursing Technician 7).

According to the testimony of professionals, it is clearly more often the essential work in interprofessional collaboration to improve patient care.

\section{Challenges to inter-professional collaboration}

Collaboration requires dialogue, communication among professionals. Most professionals reported no problems in communicating, for example, physicians who reported having a good relationship with their peers and with professionals in other categories. However, in some categories, we saw that there are relational and behavioral problems, as the little personal affinity between some professionals and their behavior has been responsible for some weaknesses in communication among professionals. Dialog difficulty, in my view, is related to the personal behavior of each one (Nurse
9). There are also references to the difficulty of accepting criticism, not seen to be constructive, and not as a quality search instrument. I have difficulty with my professional colleagues as a critical even being built, or orientation, are not always seen as positive for the improvement (Nurse 5). In other cases, nurses find it difficult to dialogue with medical professionals, especially when there is any objection concerning the patient's therapy. Other professional who is more "complicated" but try to keep a good relationship with all (Nurse 1). Sometimes, very rarely, I try to work while respecting the particular needs (Nurse 3). The physiotherapists have more resistance to one or other professional, not with a particular category. No! I think when there is a difficulty, it is more related to the type of person than the category itself (Physiotherapist 1). The difficulty of dialogue sometimes happens to some professionals, not with a specific category (Physiotherapist 7).

Most of the nursing technicians say they do not have difficulty communicating with the different professions, except for a minority that claims to have limitations with the medical profession. Yes, I relate as well as all professionals, but I feel that the medical profession does not trust our work (Nursing Technician 8).

Social workers have difficulty with nurses; they feel the nurse do not want to establish interexchanges and feel frequent communication barriers by the medical profession. Yes, especially with nurses who do not seem to want to establish inter-exchanges. There are exceptions, but in general, the category where most of them identify communication difficulties is with nursing, followed by the medical profession (Social Worker 2). Most of them believe that the other categories do not know their professional duties and often confused with professionals for mutual orders. The relationship is not good as desired. There is a huge gap in the team for the participation of the social worker. The staff of the intensive care unit does not know the assignments on the team, and sometimes we confuse duties with a professional (for example calling the families to ask the presence of a family member and documents, etc...) (Social Worker 2). 


\section{Discussion}

Despite the workers feel satisfied with the job they perform and professionally happy, other feelings such as satisfaction, well-being, pleasure, are weakened motivation for organizational boundaries such as precarious ties and professional turnovers. It is apparent that the absence of good conditions in the work context can produce dissatisfaction in health workers. There are several aspects that could change this reality, as the appreciation of professionals, especially nursing technicians, whom most of them are very devalued and little heard, despite being very close in patient care. The relevance of these aspects is mentioned in other studies ${ }^{(11-12)}$, which highlight the need for the workplace to be understood as a place of recognition and personal growth, making the worker feel satisfied with the activities carried out in the context of work of the intensive care unit and to society.

Despite institutional barriers, with reduced staff, lack of materials, professional devaluation, tiredness and stress, health workers like to work in the intensive care unit, and they worry about performing quality and humane care. This is also found in other studies $^{(13)}$.

The main detected generators of stress factors for the professional Intensive Care Unit were work overload; insufficient quantity of human and material resources; high-risk procedures; low attendance and punctuality professionals; accumulation of jobs; fragile interpersonal relationships; excessive noise; the complexity of the actions; job dissatisfaction and inadequate remuneration ${ }^{(14)}$.

Similar findings were reported in another study $^{(15)}$ where it was observed that stressors of the Intensive Care Unit staff are related to an insufficient number of professionals. Such as physical structure and outdated equipment; low professional recognition by the institution, not existing career plans for improved job satisfaction of the staff; lack of institutional space to discuss the fears and anxieties; lack of continuing education, aimed at professional training to deal with the process of death/dying, and the need for psychological support for health professionals ${ }^{(15)}$.

In practice, the care provided by healthcare organizations in general and in hospitals is necessarily interpersonal, that is, it depends on the coordinated work of several professionals. This work gathered a large number of small procedures that will be completing, in a more or less conscious and agreed between the various caregivers circulating and producing the life of the hospital. In the end, what will define greater or lesser comprehensiveness of care received is the way of articulation of these practices ${ }^{(16)}$.

The interaction and teamwork are not established automatically, but requires daily learning, since vocational training, which must be used experiences working as a team, but also in everyday experiences in the workplace, through studies, discussions of cases of inter-exchanges. A team develops from the relationships established of the members and with the environment in which they live, by their practice, their actions, their thinking and their feeling. That is, what we are, it is a direct reflection of our actions and in groups this identity as well as modified is constituted ${ }^{(17)}$.

Many experts point to the joint taxation of knowledge in health teams, involving all professional categories and not only the medical professional. They point to the need for learning to deal with the dynamics of relationships and processes to interact with each other, covering not only the relationship between the teams and patients but also the relationship between members of the health teams ${ }^{(18-19)}$.

It is evident in the speech of many professionals the need for leadership to happen inter-professional collaboration. This can occur spontaneously but 
to be enhanced, it is necessary the presence of organizational devices, such as staff meetings, the inter-branch continuing education, the presence of a management system that integrates health care, research and training ${ }^{(4)}$. A leadership also is important for the management of conflicts, which are natural in social relationships. However, they must be handled properly, avoiding crystallization, which can increase the resistance to the inter-professional collaboration.

It is essential to understand the interrelationship of the different categories because the dissatisfactions and problems of the working field can be reflected voluntarily and involuntarily in attendance. This behavior is a key piece of problem solving and quality improvement.

However, the challenge to build a favorable environment for inter-professional collaboration and growth and personal satisfaction is a complex task, requiring not only the decision management but also the health professionals involved.

\section{Final Considerations}

The study revealed that fundamental aspect of inter-professional collaboration in health work, contributing to improved patient care, greater efficiency in the treatment and fewer iatrogenic. An intensive care unit, where the health of patients is severe, requiring quick responses, this interprofessional collaboration is, even more, necessary because, without the collective efforts, many resources are wasted, seriously affecting solvability of health care.

Despite the professionals recognize the need for inter-professional collaboration, workers still do their work very individualized, fragmented, with no mechanisms to facilitate this collaboration. They highlight what still happens is an exchange of information between doctors and nurses, for adjustment of some therapy, but this practice does not extend to the rest of the team. Also, another privileged moment of information exchange is the shift change, but each to their category.

There is evidence that there are numerous difficulties for inter-professional collaboration, both organizational, as in the way the teams are organized to work. There are also barriers from a personal point of view since many people are not open to new experiences and are closed to dialogue and exchange of knowledge among professionals.

The construction of therapeutic projects of patients in the collective of professionals working in the intensive care unit follows a major challenge. Health care remains predominantly in fragmented actions. The inter-professional collaboration requires support and initiative management, strengthening the practice. However, this collaboration does not occur only by decision of the managers. It is necessary to make the involvement and openness of professionals. In this perspective, the continuing education of workers constitutes a fundamental condition for the transformation of the professional do in an integrated way, in collaboration. Also, it is necessary to create spaces and deployment strategies with the institutional support to facilitate the meeting of the teams and the exchange of knowledge and sharing practices. The interaction and teamwork are not established automatically, but requires daily learning, since vocational training, which must share experiences working in teams, or create opportunities for inter-professional education.

Considering this is a study in only one service, which does not empty its importance, future studies would be important to deepen this research, seeking subsidies and strategies to reduce the challenges pointed out by professionals working in intensive care units and contribute to increasing collaboration among professionals, resulting in a more humanized, safe and comfortable care for the patient. 


\section{Acknowledgement}

The publication of this article was funded by Coordenação de Aperfeiçoamento de Pessoal de Nível Superior, under the Project 0363163 - Laboratório de Pesquisas, Ensino e Gestão do Conhecimento, da Educação e do Trabalho na Saúde.

\section{Collaborations}

Barros ERS contributed to the analysis and interpretation of data and writing the article and final approval of the version to be published. Ellery AEL contributed to the writing of the article and relevant critical review of the content.

\section{References}

1. Ministério da Saúde (BR). Política Nacional de Humanização: a humanização como eixo norteador das práticas de atenção e gestão em todas as instâncias do SUS. Brasília: Ministério da Saúde; 2004.

2. Costa JB, Costa CR, Costa CRLM, Miglioranza DC, Miglioranza EF, Versa GLGS. Fatores estressantes para familiares de pacientes em UTI. J Bras Psiquiatr. 2010; 59(3):182-9.

3. Rose L. Interprofessional collaboration in the ICU: how to define? Nurs Crit Care. 2011; 16(1):5-10.

4. Ellery AEL. Interprofissionalidade na Estratégia Saúde da Família: condições de possibilidade para a integração de saberes e a colaboração interprofissional. Interface Comun Saúde Educ. 2014; 18(48):213-4.

5. World Health Organization. Framework for action on interprofessional education \& collaborative practice. Geneva: WHO; 2010.

6. Pirolo SM, Ferraz CA, Gomes R. The integrality of care and communicative actions in the crossdiscipline practice in intensive care. Rev Esc Enferm USP. 2011; 45(6):1396-402.
7. Silva RHA, Scapin LT, Batista NA. Avaliação da formação interprofissional no ensino superior em saúde: aspectos da colaboração e do trabalho em equipe. Avaliação. 2011; 16(1):167-84.

8. Hugo PL. Comunicação interdisciplinar em saúde: importância e desafios. Nursing. 2010; 22 (257):814.

9. Camelo SHH. Professional competences of nurse to work in Intensive Care Units: an integrative review. Rev Latino-Am Enfermagem. 2012; 20(1):192-200.

10. Ricoeur P. Du texte à l'action. Essais d'hermeneutique II. Paris: Seuil; 1986.

11. Shimizu HE, Couto DT, Merchan-Hamann E. Pleasure and suffering in intensive care unit nursing staff. Rev Latino-Am Enfermagem. 2011; 19(3):565-72.

12. Silveira RS, Funck CR, Lunardi VL, Silveira JT, Avila LI, Lunardi Filho WD, et al. Percepção dos trabalhadores de enfermagem acerca da satisfação no contexto do trabalho na UTI. Enferm Foco. 2012; 3(2):93-6.

13. Silva FD, Chernicharo IM, Silva RC, Ferreira MA. Discursos de enfermeiros sobre humanização na unidade de terapia intensiva. Esc Anna Nery. 2012; 16(4):719-27.

14. Melo MB, Barbosa MA, Souza PR. Job satisfaction of nursing staff: integrative review. Rev Latino-Am Enfermagem. 2011; 19(4):1047-55.

15. Sant'Anna SR, Hennington ÉA. Micropolítica do trabalho vivo em ato, ergologia e educação popular: proposição de um dispositivo de formação de trabalhadores da saúde. Trab Educ Saúde. 2011; 9(supl 1):223-44.

16. Cardoso CG, Hennington AE. Trabalho em equipe e reuniões multiprofissionais de saúde: uma construção à espera pelos sujeitos da mudança. Trab Educ Saúde. 2011; 9(supl 1):85-112.

17. Navarro ASS, Guimarães RLS, Garanhani ML. Teamwork and its meaning to professionals working in the family health strategy program. Rev Min Enferm. 2013; 17(1):61-8. 
18. Rosa BA, Rodrigues RCM, Gallani MCBJ, Spana TM, Pereira CGS. Fatores estressores para a equipe de enfermagem da unidade de terapia intensiva. Rev Min Enferm. 2012; 16(3):454-62.
19. Hercos TM, Vieira FS, Oliveira MS, Buetto LS, Shimura CMN, Sonobe HM, et al. O trabalho dos profissionais de enfermagem em unidades de terapia intensiva na assistência ao paciente oncológico. Rev Bras Cancerol. 2014; 60(1):51-8. 